\title{
A QUESTÃO DO TURISMO EM COTIJUBA, BELÉM -PA: MUDANÇAS, PERMANÊNCIAS E (CO)EXISTÊNCIAS NO COTIDIANO ILHÉU
}

\author{
The question of tourism in Cotijuba, Belém - PA: changes, permanence and (co) existences in everyday ilhéu \\ La cuestión del turismo en Cotijuba, Belém -PA: cambios, estancias y (co) existencias en el cotidiano ilhéu
}

Nabila Suelly Souza Pereira

Universidade Federal do Pará (UFPA), Brasil

nabilapereira@hotmail.com

DOI: https://doi.org/10.18472/cvt.20n3.2020.1854

Redalyc: http://www.redalyc.org/articulo.oa?

$\mathrm{id}=115464747001$

\author{
Maria Goretti da Costa Tavares \\ Universidade Federal do Pará (UFPA), Brasil \\ mariagg29@gmail.com
}

Recepción: 29 Agosto 2020

Aprobación: 03 Noviembre 2020

\section{Resumo:}

El artículo aborda la realidad de la isla de Cotijuba, Belém-Pará, sobre los cambios, permanencias y coexistencias que enfrenta el tema turístico a partir de los cambios reverberados en el proceso de metropolización en Belém, capital de Pará. Se entiende que el turismo El desordenado, sin embargo, de extrema importancia para el desarrollo actual de la isla, se muestra como una intervención urgente en el sentido de las políticas públicas para atender los aspectos de salvaguarda de la integridad cultural y ambiental de Cotijuba. Los cambios en la reproducción del espacio en Cotijuba se construyeron a partir de una racionalidad urbana cada vez más creciente. El paisaje actual presenta formas bastante diferentes de hace diez años, con las nuevas formas también vemos nuevos contenidos. Un turismo sin casi nada que planificar, con poca interacción e identidad con la naturaleza y con escaso retorno económico a la comunidad local, lo hace parte de lo que más se acerca al centro, constituido por el puerto, lugar de intercambios y relaciones directas con el continente, un espacio muy similar a las afueras de Belém.

PalaVras-ChaVe: Turismo, Cotijuba, mudanças, permanências.

\section{ResUmo:}

O artigo aborda, a partir da realidade da ilha de Cotijuba, a mais próxima do centro de Belém, capital do Pará, sobre mudanças, permanências e coexistências que a questão turística enfrenta a partir das modificações reverberadas do processo de metropolização. Entende-se que o turismo é detentor de uma importância extrema para o desenvolvimento atual da ilha, que possui um porto, lugar das trocas e relações diretas com o continente, mostra-se como uma urgência de intervenção no sentido de as políticas públicas atentarem para os aspectos de salvaguarda da integridade cultural e ambiental de Cotijuba. As mudanças na reprodução do espaço em Cotijuba foram construídas a partir de uma racionalidade urbana cada vez mais crescente. A paisagem atualmente apresenta formas distintas de dez anos atrás, com as novas formas também se vê novos conteúdos. Sem planejamento, o turismo não oferece interação e identidade com a natureza e tão pouco financeiro à comunidade local, faz da ilha um espaço muito parecido com a periferia de Belém.

Palavras-Chave: Turismo, Cotijuba, mudanças, permanências.

\section{Abstract:}

The article discusses the reality of the island of Cotijuba, Belém-Pará, about the changes, permanences and coexistences that the tourism issue faces from the reverberated changes in the metropolization process of Belém, capital of Pará. It is understood that tourism disorderly, however, having an extreme importance for the current development of the island, shows itself as an urgent intervention in the sense of public policies to pay attention to the aspects of safeguarding the cultural and environmental integrity of Cotijuba. The changes in the reproduction of space in Cotijuba were built based on an increasingly increasing urban rationality. The landscape today presents quite different forms from ten years ago, with the new forms we also see new content. Tourism with almost nothing to plan, with little interaction and identity with nature and with little financial return to the local community, makes it part of the one that comes closest to the center, consisting of the port, the place of exchanges and direct relations with the continent, a space very similar to the outskirts of Belém. 
Nabila Suelly Souza Pereira, et al. a QUeStão do turismo em cotiJuba, BELÉM -PA: MUdANÇAS, PERMANÊ...

KEYWORDS: Tourism, Cotijuba, changes, permanence.

Palabras Clave: Turismo, Cotijuba, cambios, permanencia.

\section{INTRODUÇÃO}

Das 39 ilhas de Belém, capital do estado do Pará, Cotijuba está entre as três maiores em extensão territorial[1]. Uma vez que Belém possui mais da metade de seu território composto por ilhas, estas delineiam a paisagem da cidade demonstrando sua realidade ribeirinha, pois acompanhando a característica das cidades Amazônicas tradicionais, a capital paraense nasceu às margens do rio, que se estabeleceu como via principal para o escoamento de mercadorias e relações com outros municípios (Trindade Júnior, 2008). O rio possui forte relação com o fluxo da capital, principalmente para as ilhas e outros municípios do Pará, no entanto, assumindo, também, uma nova funcionalidade, que coexiste com as características ribeirinhas e a nova temporalidade da metrópole.

Atualmente, Cotijuba está voltada para funções turísticas e de lazer, como aponta Silva (2001). A ilha obteve o maior aumento populacional e de relações com a capital a partir da implantação da linha fluvial pela prefeitura de Belém, em 1994. No entanto, pode-se perceber que essa nova organização do espaço, ou (des) organização do espaço já aponta para alguns impactos causados pela crescente atividade turística e expansão do modo de vida urbano. Guerra (2007) já destacava alguns impactos causados pela ocupação urbana a ilha de Cotijuba ao afirmar que, a partir da análise dos dados coletados em sua pesquisa, pode-se apontar a redução no espelho das águas interiores, aumento das praias, desmatamento de área litorânea entre outros efeitos.

Nesse sentido, a pesquisa foi realizada entre os anos de 2016 e 2018. Os procedimentos metodológicos envolveram um levantamento bibliográfico acerca do caráter histórico-geográfico sobre a área de estudo em questão; levantamento documental sobre a ilha de Cotijuba e informações de Belém relacionados também a ilha; entrevistas semiestruturadas que ocorreram associadas aos trabalhos de campo no segundo semestre de 2018. Assim, neste artigo se abordará a questão turística em Cotijuba, observando como a ilha enfrenta as modificações reverberadas a partir do processo de metropolização de Belém, capital do Pará, observando as mudanças e permanências que consistem nessa ilha.

Aborda-se aqui, inicialmente, a ilha de Cotijuba incorporada ao processo de metropolização de Belém. Em seguida, busca-se apresentar as mudanças, permanências que o espraiamento do tecido urbano (Lefébvre, 2016) acabaram por influenciar na atividade turística da ilha. Finaliza-se discutindo as coexistências na relação da atividade turística e o cotidiano ilhéu a partir do crescente espraimaneto urbano da região metropolitana de Belém.

Assim, o texto é construído a partir de uma investigação no âmbito da tendência das maiores ilhas em extensão ganharem, na divisão espacial do trabalho[2], o papel de espaço de turismo e lazer no processo de urbanização de Belém. De modo que possa se observar em Cotijuba, o processo de contiguidade do tecido urbano, sobretudo no bojo da ampliação de serviços e relações antes não realizadas no local: características da metrópole.

\section{A incorporação das ilhas na metropolizaÇão de Belém: as particularidades de Cotijuba}

A metropolização de Belém inicia-se em 1960 e consolida-se nos anos seguintes. É marcada pela chegada das rodovias e incorporação de outras cidades paraenses à capital e também a integração econômica às demais regiões do Brasil . Este processo de metropolização está marcado por dois momentos que são definidos relacionados, primeiramente, à forma metropolitana compacta e confinada, e o segundo, que diz respeito à 
forma metropolitana dispersa ou desconcentrada (Trindade Júnior, 2016). Os dois momentos discutidos pelo autor, apresenta a metrópole em processo de modificação.

De acordo com Trindade Júnior (1998), junto à reestruturação urbana, os assentamentos de baixa renda migram das baixadas localizadas nas áreas então centrais para novos vetores de expansão, redesenhando a forma espacial metropolitana e incorporando localidades em direção a Augusto Montenegro e BR 316. Nessa via, as ilhas também estão inclusas a essas modificações da metrópole, cada uma com suas particularidades assumindo novas relações, pois as ilhas estiveram como importante vetor de integração à metrópole a atividade balneária. Sendo a ilha de Mosqueiro e Caratateua ligadas por pontes e a ilha de Cotijuba (ver Figura 01) pela regulamentação do transporte fluvial (Guerra, 2004).

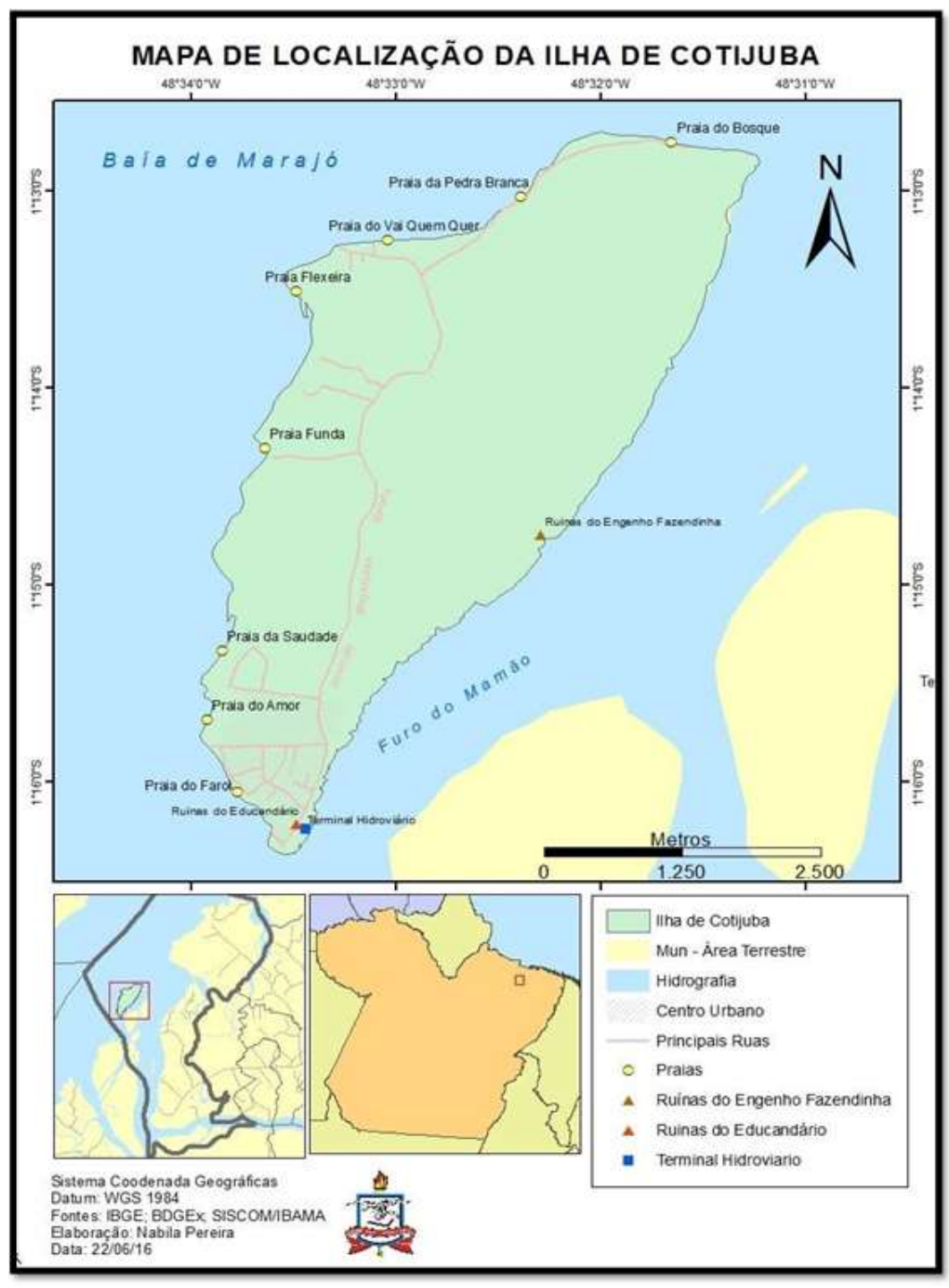

FIGURA 1

Localização da Ilha de Cotijuba

LAIG/UFPA, 2016 (Organizado por Nabila Pereira).

Junto ao processo de metropolização, a produção de um espaço de fuga do cotidiano urbano faz-se presente. A procura por espaços onde pode-se entrar em contato com a natureza. Nesse sentido que a o papel das ilhas como espaço de lazer na divisão espacial do trabalho da metrópole belenense configura-se como resultante da produção do espaço urbano vinculada ao processo de metropolização. Para Lefebvre (2004), o que ocorre é o espraiamento do tecido urbano, à medida que este não significa apenas o domínio edificado das cidades e 
sim o conjunto das manifestações do urbano, uma segunda residência, uma rodovia configuram-se parte do tecido urbano. Destarte, este espraiamento do tecido urbano desencadeia, também, a produção de espaços periféricos. Huffner (2011) chama atenção para isso ao afirmar que:

[...] periferização no Brasil e em Belém está intimamente ligada à fatores como pobreza, condições de habitação precárias, encarecimento da moradia no centro entre outros. Sendo este processo visível e intenso nas ilhas de Belém, principalmente Mosqueiro, Outeiro e Cotijuba. O Turismo nestes locais acentua-se a migração de pessoas que não trabalham com a terra nem com a pesca buscando uma moradia barata e a exploração de atividades novas como as ligadas ao turismo, gerando especulação imobiliária, posse ilegal de terrenos, loteamento irregular, e desmatamento (Huffner, 2011, p. 91).

Assim, Cotijuba tem suas maiores relações com a metrópole intensificadas mais tardiamente. De acordo com Huffner (2011), na década de 50 a ilha já apresentava maior ocupação a partir de loteamentos realizados como curral eleitoral para os apoiadores do governo de Alexandre Zacarias de Assumpção (1951-1956). Na década de 1980, após o desligamento da colônia penal, a ocupação desordenada passa a ser intensificada e tem-se o início da atividade turística na ilha. Contudo, é a partir da implantação da linha fluvial, que facilita o acesso da população da metrópole, que Cotijuba vivencia maiores reestruturações em seu espaço, a partir de uma realidade mais urbana. Silva (2001), ao analisar os dois primeiros meses após a criação da linha fluvial:

verifica-se um crescimento exorbitante no número de visitantes. Segundo dados da CTbel (Companhia de Transporte do Município de Belém), houve um incremento de cerca de $200 \%$, sem considerar as pessoas que chegavam à Ilha através dos barcos da ABIC- Associação dos Barqueiros da Ilha de Cotijuba. Estima-se que, em novembro de 1994, aproximadamente 20 mil pessoas visitaram Cotijuba (Silva, 2001, p. 20).

O processo de ocupação da ilha de Cotijuba também obteve maior intensidade após a implantação da rede elétrica (2005) quando as visitações à ilha passam a intensificar e o processo de ocupação e compra de terrenos para construção de casas de veraneio, o chamado turismo de segunda residência, cresce em grande medida. No Quadro 1 observa-se uma tentativa de periodização dos principais acontecimentos ocorridos na ilha que obtiveram importantes influências em sua ocupação. 


\author{
QUADRO 1 \\ Cronologia da ocupação da Ilha de Cotijuba
}

\begin{tabular}{|c|c|}
\hline Periodo de inicio & Descrição do acontecimento \\
\hline Por volta de 1874 & $\begin{array}{l}\text { Funcionou na Ilha um engenho de branqueamento de arroz e, } \\
\text { apos a sua extinça, a Ilha foi apropriada por uma senhora de } \\
\text { nome Joana, no entanto, algumas pessoas que trabalhavam no } \\
\text { engenho permaneceram na ilha. }\end{array}$ \\
\hline 1932 & 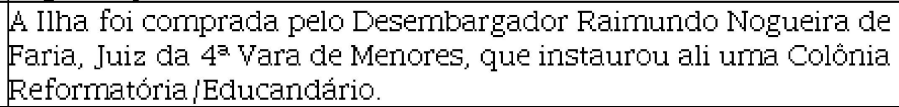 \\
\hline 1945 & $\begin{array}{l}\text { A Cooperativa agricola japonesa era composta por } 18 \text { familias de } \\
\text { origem japonesa, responsaveis por fornecer alimentos agricolas } \\
\text { para os alunos da colonia reformatória e por vender parte da } \\
\text { produçăo nos mercado do ver-o-peso. Permaneceram no local } \\
\text { por cerca de } 20 \text { anos. }\end{array}$ \\
\hline 1947 & $\begin{array}{l}\text { A Ilha foi repassada ao Governo do Estado do Pará, periodo em } \\
\text { que a Colonia passa a experimentar um processo de decadencia. }\end{array}$ \\
\hline 1968 & $\begin{array}{l}\text { Governo do Estado transformou a Colônia lEducandário em } \\
\text { Colónia Penal, que passou a ser vinculada à Secretaria de } \\
\text { Segurança Pública do Estado do Pará, recebendo presidiários com } \\
\text { alto grau de periculosidade. }\end{array}$ \\
\hline 1978 & $\begin{array}{l}\text { A Colônia Penal foi totalmente desativada, no entanto, muitos } \\
\text { remanescentes da Colônia, seus familiares e antigos funcionários, } \\
\text { passaram a residir em Cotijuba. }\end{array}$ \\
\hline 1980 & $\begin{array}{l}\text { A Ilha começa a se firmar como um dos pólos de lazer da cidade } \\
\text { de Belem, começando assim a receber visitantes com esse intuito. }\end{array}$ \\
\hline 1994 & $\begin{array}{l}\text { A implantaçăo da linha diária do navio de passageiros mantida } \\
\text { pela Prefeitura Municipal de Belém (PMB): um dos principais } \\
\text { marcos da ocupação e visitaçấo da ilha, pois se configura a } \\
\text { relaçäo diária da metrópole com a ilha com mais facilidade de } \\
\text { acesso. }\end{array}$ \\
\hline 2000 & $\begin{array}{l}\text { Inauguração do terminal hidroviário Poeta Antônio Tavernard } \\
\text { pela FMB: o porto muda de localidade podendo assim atracar } \\
\text { embarcaços maiores. }\end{array}$ \\
\hline 2002 & Instalaçầo da eletricidade na ilha. \\
\hline
\end{tabular}

Elaborado pelas autoras

É importante ressaltar que, de acordo com o quadro a cima, a partir da década de 1980, houve implementações de equipamentos urbanos gerenciadas pelo poder público, demonstrando assim o espraiamento do tecido urbano e as modificações na configuração espacial da ilha. Diante de uma melhor facilidade de acesso e de maiores ofertas de serviços de cunho urbano, a ilha passa por inúmeras modificações socioespaciais. Estas modificações são intensificadas pelo aumento progressivo da atividade turística e pela substituição, em grande medida de modo de produção agrícola e da pesca, o que configura as populações tradicionais ilhéus pela atividade de serviços com uma dependência maior da atividade turística.

\title{
3. A questão do turismo em CotiJuba: mudanças, Permanências e (co)existências NO COTIDIANO ILHÉU
}

De acordo com a Organização Mundial de Turismo - OMT, turismo é a atividade de um viajante, com pernoite, fora do seu entorno habitual. Mas como então caracterizar aqueles moradores de Belém que viajam para Cotijuba, há 40 minutos do continente? Ao analisar tais questóes para a ilha de Cotijuba, essa sempre se torna uma das questões mais conflitantes na discussão. No entanto, entende-se aqui neste trabalho que a vivência de quem viaja é o que o faz turista ou não., configurando, assim, no que se entende por "turismo de excursionismo", em que se passa menos de 24 horas no destino. Isso porque, mesmo sabendo que Cotijuba faz 
parte de Belém, as relações trocadas entre os que vem de Cotijuba para Belém é demasiadamente diferenciada daqueles que visitam a ilha. Nesse sentido, concordamos com Ribeiro (2007), pois

Os objetivos das organizações oficiais do turismo, como a OMT, dizem respeito à construção de estatística que confiram bases à promoção econômica do turismo acabando por se distanciar dos objetivos de compreensão do fenômeno dispensados pelas ciências dedicadas às problemáticas da vida social. $\mathrm{O}$ excursionismo sendo uma prática condicionada a viagem, objetivando o desenvolvimento de atividades de lazer e com a clara intenção de retorno não pode deixar de ser incluso entre as práticas turísticas (Ribeiro, 2007, p. 48).

Resolver questões burocráticas em órgãos oficiais, fazer exames médicos complexos, compras de mantimentos, trabalhar, estudar etc. são características de relações trocadas entre os que vêm de Cotijuba a Belém cotidianamente. Se caracterizam em relações pertinentes ao mundo urbano, mundo do trabalho, o cotidiano do tempo rápido, da produção do espaço pelo/para o capital. As relações são da metrópole, com o tempo rápido da metrópole. Onde também, concomitantemente, se observa o cotidiano da vizinhança, da família, porém, as relações trocadas aqui, destes que de lá vem, diferem das relações trocadas lá dos que daqui vão. A cidade, Belém, local e meio das interações complexas do urbano, produz assim, seus turistas peculiares viajantes dentro de um espaço curto, com espacialidades distintas e temporalidades diversas, onde aqui, as relações trocadas é o que os distingue (Lefebvre, 2016).

Feitas as considerações sobre o turista belenense de Cotijuba, caminha-se, então, para o turismo realizado na ilha. Em outros momentos deste texto, pode-se observar o turismo como

importante organizador do espaço e produtor de novas relações. Como prática social e atividade econômica é um importante vetor de produção do espaço (Cruz, 2008).

No processo de produção do espaço em Cotijuba, a comunidade local, o mercado, o estado e os visitantes produzem um espaço dos afazeres turísticos que acabam ganhando inerência ao cotidiano ilhéu. A organização da comunidade para o recebimento do visitante passou a delinear, há poucas décadas, um novo espaço na ilha, desencadeando novas espacialidades, temporalidades e (co)existências. Nesse sentido entendese que

não são apenas Estado, mercado e turistas que produzem os espaços relativos aos fazeres turísticos, mas também as sociedades que vivem nesses lugares, parte delas transformada, por força de novas contingências, em empreendedores turísticos ou, mesmo em muitos casos, atuando como contra-racionalidades às determinaçōes hegemônicas. A produção do espaço envolve seu uso e apropriação e, neste caso, o conflito termina por ser inerente ao processo (Cruz, 2008, p. 33).

A atividade turística se desenvolveu junto ao processo de metropolização de Belém e, nesse contexto, as relações urbanas passaram a aumentar na ilha, tanto nas relações socioespaciais quanto na paisagem. Contudo, o mercado turístico ali ainda encontra-se muito precário, o que sugere que o turismo fora se delineando sem ordenamento, junto a ele, a comunidade local também fora buscando se adaptar.

Entendo que a extensão territorial da ilha é bastante considerável, percebe-se que o uso e apropriação do território se dá de maneira diferenciada, de acordo com a localização geográfica no lugar. As praias de Cotijuba e o contato com a natureza, são potenciais inegáveis para atrair diversos visitantes, certas épocas do ano.

Mesmo no universo da atividade turística, há as subdivisões das atividades também de acordo com espaço geográfico na ilha. As práticas turísticas se configuram ali basicamente em: Excursionismo, Turismo de segunda residência, Ecoturismo, e estão presentes algumas iniciativas de turismo de base comunitária. Essas visitações ocorrem, em grande medida, nas férias escolares, finais de semanas e feirados.

Saindo do continente, a travessia da ilha se faz apenas via fluvial, onde barcos saem de dois pontos diferentes de Belém. O mais tradicional e de maior repercussão é o de Icoaraci, que faz o trajeto até o Terminal Hidroviário de Cotijuba. Este transporte é diário e regular. É realizado por um barco, mais conhecido como "barcão", que suporta em torno de 300 passageiros.

O turismo realizado em Cotijuba, na divisão espacial do trabalho, no processo de metropolização de Belém, se estabeleceu como espaço de lazer das camadas mais populares do continente. Huffner (2011), afirma que 
o turismo em Cotijuba, em grande medida, é realizado por visitantes de condição sócio econômica de renda baixa e este fato contribui para compreender as peculiaridades locais do turismo, tais quais seus possíveis impactos.

De acordo com Ribeiro (2007, p. 46), o turismo excursionista também é caracterizado por visitantes, em grande medida, economicamente desfavorecidos, visto que uma das principais características é a "não existência de grandes dificuldades de acessibilidade no tempo e custo de deslocamento". O turismo excursionista realizado na ilha demonstra a desorganização e os problemas que formam a partir de uma crescente visitação sem o devido cuidado do poder público para um ordenamento territorial, obedecendo ao plano diretor e às peculiaridades de Cotijuba.

$\mathrm{Na}$ ilha, também ocorrem as práticas de piquenique/passeio, as quais configuram em um turismo considerado "agressivo". Os turistas vindo por essa modalidade passam apenas algumas horas no lugar. Chegam pela manhã e vão embora ao final da tarde, também ficam na praia mais próxima do porto onde o barco fica atracado, culminando assim, em não haver despesa com transporte dentro da ilha. Tendo em vista que a quantidade de visitantes é considerável, o pensamento de possibilidade de ganhos com essas visitações está sempre no imaginário dos comerciantes da porção sul. No fim de tarde, como mostra a Figura 2, os passageiros se dirigem ao trapiche da fábrica de gelo para retornar a suas residências, por meio do barco Santo Expedito, com festa e som de aparelhagens.

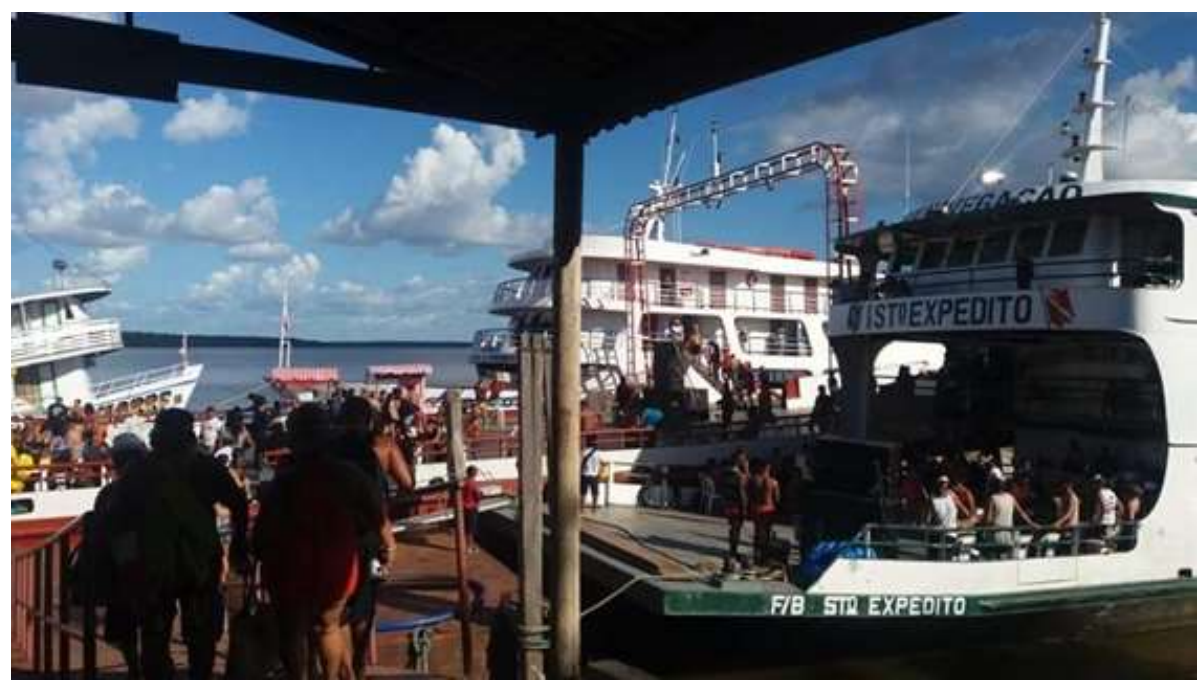

FIGURA 2

Embarque dos passageiros

Pereira, 2018.

O turismo excursionista é o que caracteriza as viagens dos barcos de passeios citados anteriormente. Mas também, se configura na maioria das práticas turísticas atualmente realizadas na ilha de Cotijuba. As praias receptoras desse tipo de turismo são nas praias do Vai-Quem-Quer e do Farol, com maior incedência nesta. A visita caracteriza-se por baixo custo, acessibilidade, as redes de circulação e o provimento de uma infraestrutura básica para as visitas, foi o que provocou a incidência desse turismo em Cotijuba, sobretudo, entendendo-se que tal prática fora a primeira a ser disseminada na ilha.

Para quem vem de Belém pelo porto de Icoaraci, e aporta no terminal hidroviário, o primeiro contato com os ilhéus se dá logo no terminal e depois, na praça central. Logo na entrada se forma um corredor com onze vendedoras de produtos locais, mais especificamente de lanches produzidos por elas. São bolos, coxinha, sucos de frutas regionais, entre outras coisas. Essas comerciantes trabalham todos os dias ali, mas a principal clientela delas são os turistas, que ali chegam e se espraiam na ilha para diversas localidades. 
As vendedoras da praça são as que todos os dias ali, em alta e baixa temporada, recebem os turistas e podem observar o fluxo diário da ilha. Essas vendedoras são mulheres provenientes de outras localidades do estado, moradoras ou não residentes do lugar, porém trabalham lá todos os dias.

Sugere-se que o motivo para estarem ali atualmente está relacionado a questão de produção de moradia, busca por trabalho no processo de metropolização de Belém. Essas não aderiram a atividade turística após o fenômeno ser estabelecido no local, e sim, por motivos outros, buscaram a ilha para sua moradia e, assim, entraram para o ramo de vendas aproveitando o contexto do turismo.

Os principais aspectos que revelam as alterações no uso turístico da ilha, são: as visitas, que antes eram concentradas na Ilha do Farol, se espraiaram por outras localidades; o turismo de segunda residência; facilidade para chegar a praia do Vai-Quem-Quer, expansão de barracas de bares e restaurantes tomando quase todo o espaço da areia da praia.

Além da praia do Farol, outra praia que também tem concentração de turistas com oferta de infraestrutura é é a praia do Vai-Quem-Quer. Nesta também se percebe uma prática turística excursionista, porém com público um pouco mais diferenciado, pois pela sua distância do terminal hidroviário, os frequentadores de antes, eram os que buscam uma praia mais bucólica e afastada das características urbanas. Na praia do VaiQuem-Quer é realizada, em diversas épocas do ano, festas de aparelhagens com djs que tocam reggae a festa inteira, o que configura numa restrição de público para os bares que realizam essas festas. Esta é uma praia que sofreu um pouco mais de modificação, de acordo com entrevistados, pois ela, não possuía essa paisagem que tem agora, os visitantes tinham outro perfil.

Essas modificações se deram pela maior facilidade de acesso e aumento de estrutura para recebimento dos visitantes. As motorretes, mostrada na Figura 3, são veículos introduzidos há menos de dez anos, atualmente fazem o trajeto à Praia do Vai-Quem-Quer, dando rapidez maior que os chamados bondinhos e charretes que possui esse nome pelo fato da distância com relação ao terminal hidroviário,. As motorretes são motos adaptadas a charretes que podem levar cerca de 6 a 8 passageiros de uma só vez. Há quem busque aspectos mais tradicionais da ilha e optem pelo trajeto de charrete, puxada pela tração animal, ou mesmo os tradicionais bondinhos (ver Figura 4). No entanto, as motos são o transporte que cresce na ilha, sem qualquer fiscalização, e oferece o serviço de locomoção às praias com rapidez.

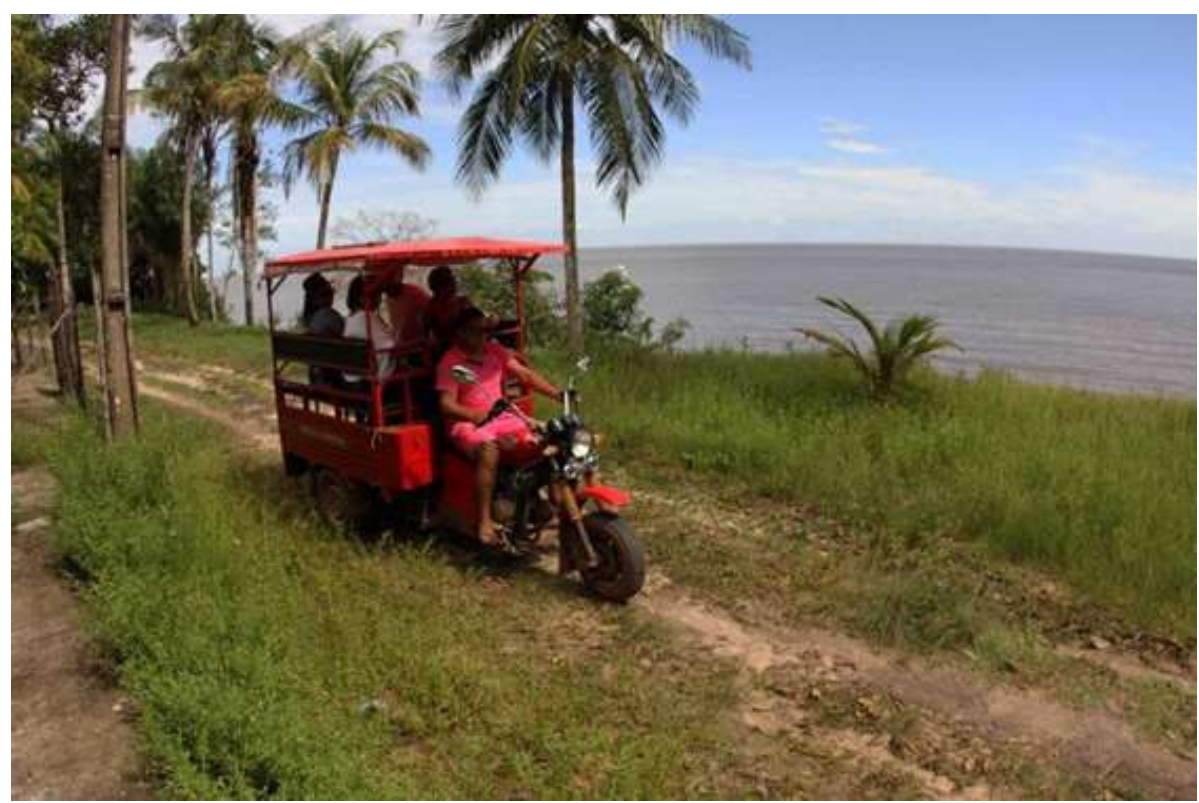

FIGURA 3

Motorrete de Cotijuba

Martins, Cristino. 2017 


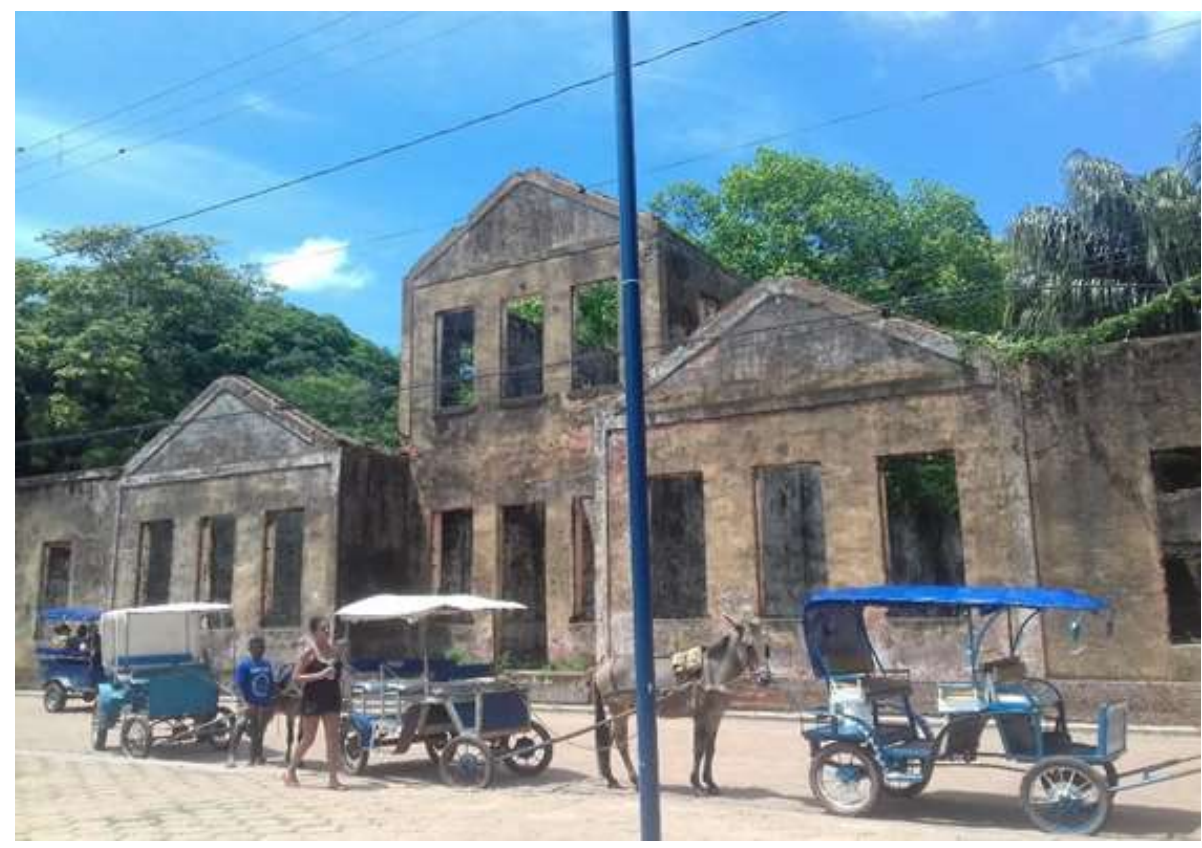

FIGURA 4

Charretes de tração animal de Cotijuba

Santos, Bruna. 2017.

Muito se houve também sobre a dependência que a atividade turística gerou aos moradores da ilha, principalmente aos que residem próximo das praias com maior visitação e próximo à área mais urbana da ilha. A atividade turística enquanto atividade econômica que deveria ser uma opção de desenvolvimento para Cotijuba e contribuir como renda extra dos ilhéus, acabou tornando-se a única atividade econômica para muitos moradores da ilha, que com o aumento da competitividade, passou a sentir uma decadência na oferta de serviços e no que conseguia arrecadar em tempos atrás.

Diante disso, em entrevista, percebeu-se as fragilidades que a atividade turística acabou adquirindo e instalando na ilha para um melhor aproveitamento das visitações:

[...] por incrível que pareça, antes o público era outro, deixava mais renda pra ilha. Hoje não! O público anterior valorizava mais a natureza, não tinha o tanto de casa que tem hoje. [...] veio o progresso, mas também veio muita coisa ruim junto (Morador, 63 anos, entrevista realizada em julho de 2018).

O progresso o qual o morador comenta na entrevista é a mudança realizada na ilha nesses últimos anos, destacando os equipamentos geográficos, a energia elétrica, a abertura de mais ruas, a entrada da companhia de telefone.

\subsection{A questão do turismo de residência na Ilha.}

Para além do turismo excursionista, mais praticado nas praias do Farol de do Vai-Quem- Quer, a ilha de Cotijuba, nos últimos anos, teve um significativo aumento da prática turística chamada de segunda residência, com a instalação de loteamentos. $\mathrm{O}$ turismo de segunda residência se configura em:

[...] um estabelecimento de um vínculo mais forte com espaço utilizado para a respectiva prática, o que pode ser compreendido ao se considerara materialidade estabelecida por este, representada pela residência secundária, dando forma a um tipo de turismo mais sedentário, ou seja, marcado por uma regularidade e uma intensidade de saídas e retornos (Ribeiro, 2007, p. 37). 
As praias do Amor e da Saudade são as que se enquadram nas receptoras do turismo de segunda residência na ilha de Cotijuba. Dentre essa prática de apropriação do espaço, de acordo com entrevista realizada, convém destacar que as relações de compra e venda de terrenos para o fim de segunda residência são realizadas por um mercado não específico, ou seja, feita por moradores com terrenos extensos, ou pessoas que compram um terreno maior e fazem loteamentos de terrenos médios e pequenos para vendas. A especulação imobiliária feita por agentes ou corretoras ainda não é realizada na ilha.

O turismo de segunda residência também se configura em uma problemática muito disseminada pelos moradores locais pois, o aumento de loteamento desencadeia no aumento de necessidades de infraestruturas adequadas, como o saneamento e abastecimento de água, assim, a produção de outras moradias desencadeia em mais usos de fossas, poços artesianos, energia e retirada da cobertura vegetal. Nesse sentido a moradora afirma que

[...] agora você imagina: o cara compra um terreno grande, divide ele em três e vende todos os três para três famílias diferentes. São três fossas, três poços e eles 'limpam' todo o terreno, sai tirando tudo. É assim que tem acontecido aqui. Tem gente que chega aqui e parece cupim, vai destruindo tudo (Diarista, moradora, 27 anos. Entrevista realizada em julho de 2018).

Apesar do turismo ter se tornado a atividade econômica mais dinamizadora realizada na ilha, muitas críticas partem dos moradores pelos efeitos que essa atividade desencadeia. O turismo excursionista e o turismo de segunda residência, aos seus pontos, sempre deixam seus impactos na paisagem local e no cotidiano de quem tem maior contato com o turista. Acerca disso, Paes-Luchiari (1999, p. 153) afirma:

O turismo de segunda residência, característico do turismo sedentário está diretamente associado à urbanização acelerada, à intensificação de especulação imobiliária, à pouca geração de lucros para a comunidade receptora, à degradação de extensas áreas e ecossistemas naturais para a construção civil eà influência dos turistas nas comunidades em função de sua força política e econômica. Ou seja, mesmo estando marginalmente associado à indústria turística, ele é responsável por uma infinidade de problemas relativos à urbanização turística. (Paes-Luchiari, 1999, p. 153).

A nova organização do espaço incluindo os que chegaram recentemente e os que continuam a chegar, transforma toda configuração da paisagem, pois cria mais espaços de venda de mantimentos, de materiais de construção e aumenta o fluxo de transporte dentro da ilha. Para além disso, desencadeia também formas de criminalidade que para os que vivem na ilha era, até então, uma prática desconhecida: os arrombamentos de residências. Assim, a moradora conta “[...] essa ilha já foi mais visitada. Aqui era melhor a vida, a gente não se preocupava com assalto. Moro aqui pelo sossego e tranquilidade, mas está ficando difícil...hoje se vê tráfico de drogas, assalto (Comerciante, 54 anos, morador, entrevista realizada em julho de 2018)."

As mudanças nos hábitos dos ilhéus tornaram-se necessárias, com relação a proteção, cuidado e no que se configurava como liberdade na ilha. Em entrevista realizada, percebeu-se que os hábitos cotidianos de dormir na parte externa das casas, ter poucos acessórios de segurança nas casas como grades e trancas, andar pela rua à noite e à pé, são hábitos que paulatinamente vão se alterando. A racionalidade urbana de uma periferia, que traz consigo o aspecto de insegurança e violência assola também para onde se espraia o tecido urbano.

\subsection{As coexistências na Ilha: outras propostas para o turismo.}

Se afastando um pouco mais da área central da Ilha, que compreende a parte sul, chega- se onde as relações se realizam com um tempo mais lento, o que se percebe é que ao se afastar do centro a temporalidade e a espacialidade vai negando uma racionalidade mais urbana e a floresta e o rio vão se tornando mais inerentes ao cotidiano ilhéu. As casas parecem mais afastadas uma das outras e a oferta de serviços até parece inexistente. Contudo, é nesse cenário que se delineia um lugar propício para a ocorrência da prática turística conhecida como turismo ecológico.

O turismo ecológico é praticado à oeste da Ilha, na praia Funda (ver Figura 5), localizada entre a praia da Saudade e praia da Flexeira. O turismo de segunda residência desencadeado na praia da Flexeira capta a 
centralidade desenvolvida na praia do Vai-Quem-Quer, onde pode-se observar uma organização turística de serviços (pousadas, bares, restaurantes, pontos de transporte). Todavia, a praia Funda encontra-se distante da parte central (cerca de 20 minutos de percurso de charrete), e distante também da parte um pouco mais urbanizada da praia do Vai-Quem-Quer. Enquanto um enclave entre as praias, a Funda recebe visitantes o ano inteiro. nas temporadas de férias, finais de semana e feriados.

A atividade turística realizada na Praia Funda possui uma organização especial para o público que a frequenta. $\mathrm{O}$ contato com a natureza e a tranquilidade é um dos atributos mais disseminados por quem organiza o espaço turístico por lá, espaço esse que não possui grandes cadeias e redes de serviços e acompanhando uma racionalidade da comunidade tradicional, o que possivelmente também é um dos atributos de venda no local, como atrativo turístico.

A Praia Funda possui aproximadamente 2 pousadas, que de certa maneira se apropriaram daquele espaço para a comercialização da paisagem. Como um espaço privativo, recebe algumas atrações durante o ano tais como festas de músicas regionais organizadas pelos proprietários das pousadas. Uma vez que a Praia Funda não possui um fácil acesso, é distante da área onde se concentra mais serviços, o visitante que ali frequenta não se caracteriza como o excursionista, que busca diminuir ao máximo os custos e o tempo no lugar. Também não o turista de segunda residência que ali frequenta, pois a pratica de loteamento ainda não está disseminada nessa porção da ilha.

A organização do espaço ali ainda busca reservar as raízes da ocupação turística na ilha, da busca pelo bucólico e regionalidade.

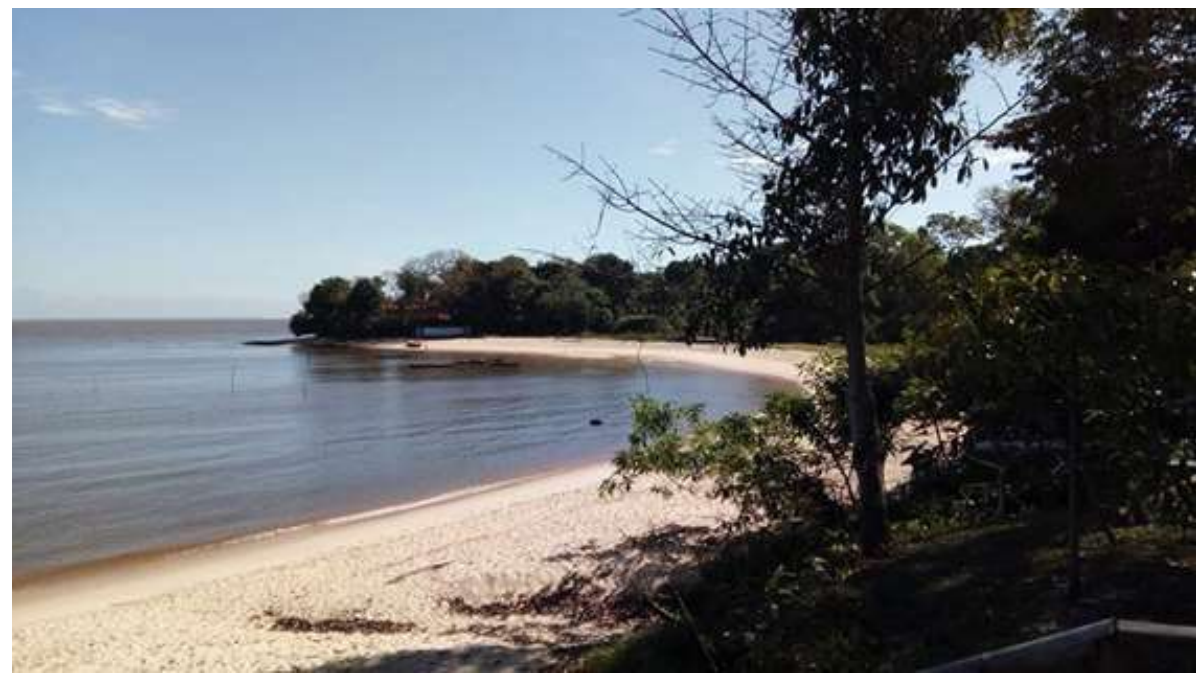

Figura 5. Orla da Praia Funda.

Pereira, 2018

Em cada lugar dentro da ilha, o espaço produzido pelas práticas turísticas mostra a fuga do urbano, do tempo rápido da produção de um espaço para o capital. $\mathrm{O}$ tempo lento do lazer, ao que parece, também é heterogêneo que recebe gradativamente o tecido urbano se espraiando. A apropriação do espaço pelo turismo repertoria novos usos e novas paisagens na ilha, mas também, resistentes ali, encontram-se as permanências, por conseguinte, as contiguidades que dão as relações socioespaciais novos conteúdos. Nessa via acredita-se:

[...] o estilo de vida urbano, atualmente, tem-se expandido e coexiste com modos de vidas, outras temporalidades no espaço geográfico. Talvez, um dos maiores fenômenos sociais que possibilita essa expansão seja a atividade do turismo, reunindo necessidades psicossociais, como também, o consumo dirigido, criando simulacros da realidade e fetiche espacial de uma natureza intocada e endeusada, separada do homem, segregando e excluindo pessoas no seu processo de desenvolvimento (Souza, 2008, p. 109). 

PERMANÊ...

Nessa dinâmica, que o espaço segue sendo produzido, nas relações cotidianas denunciadas no lugar, sob o efeito e causa dos agentes exógenos e sob uma racionalidade hibrida, entre o novo e o antigo, o "progresso" e o rústico. Assim, constrói-se diversas possibilidades de reprodução social, nesse momento do texto, tratando-se da atividade turística como produtora e organizadora do espaço, tem-se agora, o turismo de base comunitária como discussão, desprendendo-se de um turismo de sol e praia a essa altura, atravessando à porção leste da ilha de Cotijuba, chegando às comunidades Fazendinha e Poção (ver Figura 6).

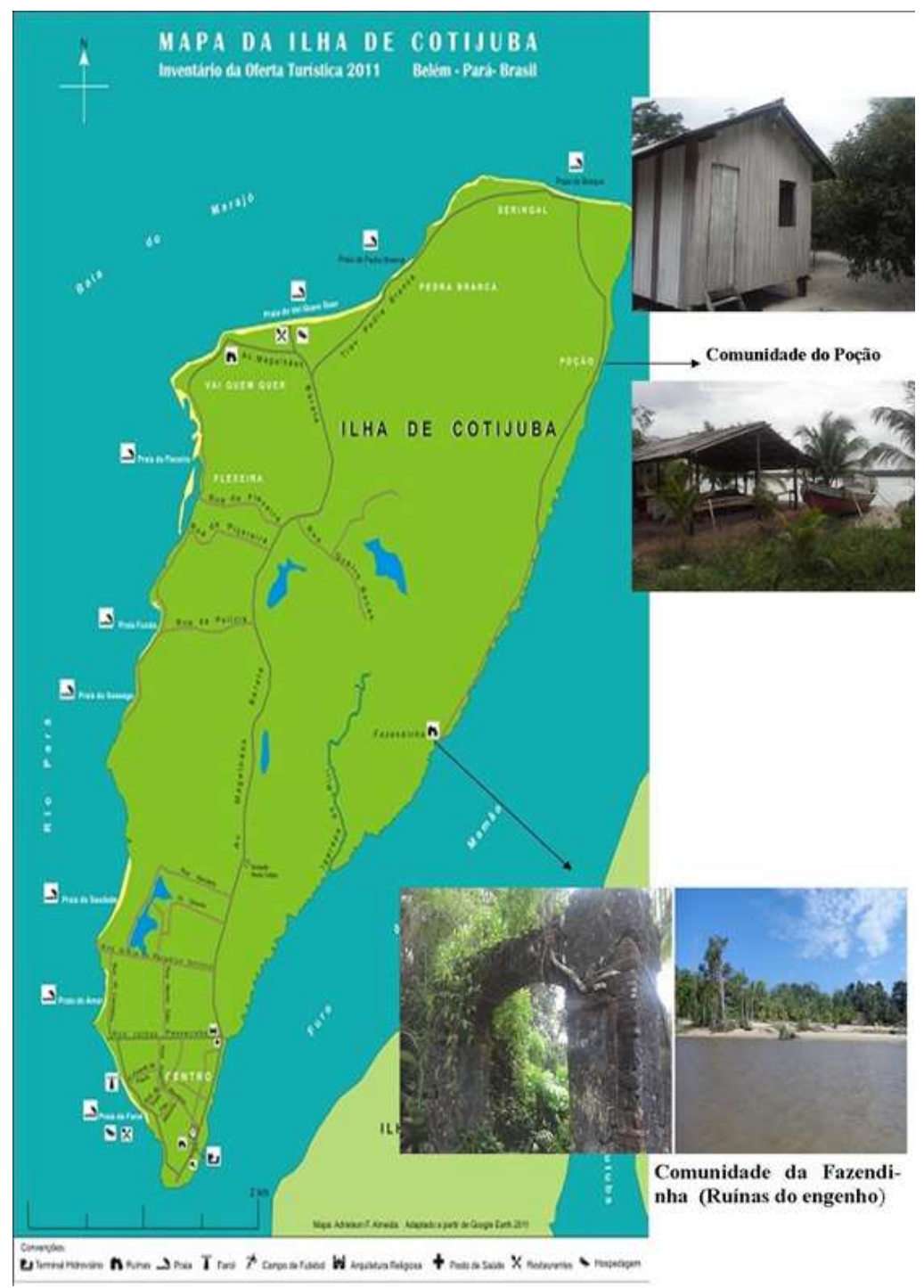

FIGURA 6

Mapa da Ilha de Cotijuba ilustrando as comunidades do Poção e Fazendinha Huffner, 2016; Belemtur, 2011

A comunidade Fazendinha localiza-se a cerca de 18 quilômetros de distância do terminal hidroviário de Cotijuba, com difícil acesso a esta porção da ilha, sem transporte regular que realize este trajeto, esta comunidade permanece afastada da área mais central da ilha. As comunidades Fazendinha e Poção ainda resistem no modo de vida mais rural, da agricultura, pesca e artesanato. De acordo com Ecomuseu da Amazônia / Fumbosque (2016) nessas comunidades $80 \%$ recebem apoio financeiro de programas sociais e a renda mensal média de $90 \%$ deles é de apenas um salário mínimo.

Essa é a parte da ilha em que o modo de vida se configura ribeirinha. A dependência da pesca de camarão, peixes e coleta do açaí é muito comum nessas comunidades. Em visita técnica pelas comunidades, pode- 
se perceber muitas pequenas embarcações atracadas no "quintal", que por sinal, se estende ao rio. Essas embarcações são o instrumento de trabalho de muitas famílias dali, mas também é seu veículo de locomoção para as outras partes da ilha e para o continente.

As residências nessas comunidades, que estão mais a beira do rio, geralmente possuem uma estrutura erguida do chão para a proteção de invasão das águas em tempo de maré cheia. São casas de madeira, com terreno extenso onde é cultivado diversas plantações e criação de animais. A Figura 7 mostra uma casa de uma família ribeirinha erguida do chão, vê-se também plantações de açaí para a subsistência da família e a venda de um pouco do excedente, o ribeirinho cultiva o açaí no quintal da sua casa.

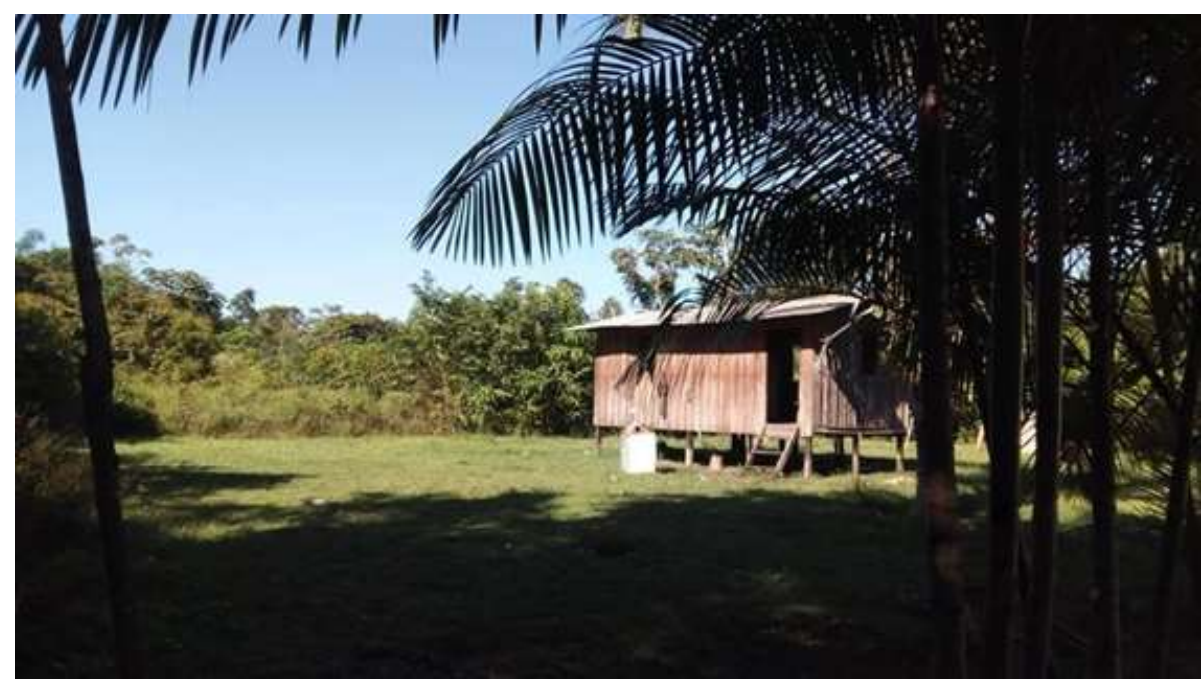

FIGURA 7

Casa de família ribeirinha

Pereira, 2018

São nessas comunidades, onde ainda se tem muito das tradições e modo de vida dos primeiros moradores da ilha que o turismo de base comunitária TBC foi implantado. De acordo com Mielke (2009), o turismo de base comunitária pode abrir novas possibilidades de trabalho para o conjunto de mão de obra familiar, contribuindo no aumento de renda e na melhoria das condições de vida da população local. Para além do aumento da renda familiar, deve-se pensar na construção de parâmetros que contribuam para a manutenção do modo de vida que os moradores locais estão habituados a viver no cotidiano. Nessa via

De fato, a atividade turística regional/local deve primar pelo respeito ao patrimônio natural e cultural do meio em que ela se desenvolve. Além disso, a participação das populações locais é considerada um elemento-chave para a realização da sustentabilidade, o que significa dizer que as populaçóes locais devem ser promotoras e, ao mesmo tempo, beneficiárias da atividade turística fomentada em âmbito regional/local (Mielke, 2009, p. 10).

No sentido de valorização do patrimônio cultural e natural do cotidiano dessas comunidades, o Ecomuseu da AmazOnia/FUMBOSQUE[3] desenvolveu um projeto de TBC valorizando os saberes e fazeres dos moradores locais, e suas insularidades - o modo de vida peculiar de quem mora nas ilhas (o espaço percebido), e suas ilheidades - os imaginários cotidianos, a dimensão simbólica do espaço (o espaço vivido) (Diegues, 1998).

Para a obtenção do projeto de TBC nas comunidades de Poção e Fazendinha o Ecomuseu da Amazônia/ FUMBOSQUE precisou trabalhar em parceria com a comunidade no sentido de identificação dos objetos/ relações que poderiam servir como atrativo turístico de visitação. Com efeito, a identificação do patrimônio natural e cultural daquela comunidade fez- se necessário.

O início do processo de planejamento para o desenvolvimento do turismo de base comunitária na região insular de Belém, capitaneado pelo Ecomuseu da Amazônia, se deu a partir da percepção das demandas e possibilidades de projetos a serem 
implantados, e que consistiu na inventariação patrimonial das comunidades e de seu território. A identificação do patrimônio foi feita de forma participativa, tendo como metodologia a elaboração de biomapas, que são representações gráficas/artísticas contendo o patrimônio preconizado e valorizado pela comunidade (Belém, 2016, p. 11).

Assim o Ecomuseu da Amazônia passou a trabalhar com as comunidades pautado em quatros princípios norteadores:

- O empoderamento e pertencimento comunitário perante a atividade turística e o seu território;

- A capacitação para o TBC;

- A estruturação do destino;

- A educação patrimonial e ambiental comunitária.

Dessa forma iniciou-se as atividades com a participação, também, da Secretaria de Estado de Turismo SETUR, onde reuniões eram marcadas a convite do Ecomuseu da Amazônia aos comunitários, e as atividades foram ganham materialidade perante a aceitação dos ilhéus. O projeto consistiu na produção de um roteiro de visitação denominado: Roteiro Patrimonial de Visitação. Nessa via, os comunitários são os que fazem todo o processo de recebimento dos visitantes, as falas explicativas dos pontos selecionados e durante o percurso demonstram as atividades realizadas por eles em seu cotidiano. Além de incluírem, também, uma parada no engenho fazendinha.

O Roteiro está estruturado em 16 pontos de visitação, contemplando o patrimônio histórico, cultural e natural das comunidades, iniciando pelas ruínas do engenho da Fazendinha, passando pelas residências dos mestres barqueiros, artesãos, agricultores e piscicultores, onde em cada ponto é possível aprender sobre as atividades tradicionais exercidas na comunidade, experimentar a comida, conhecer o cultivo de peixes regionais e conhecer o conhecer o artesanato local (Belém, 2016, p. 14).

Em busca de uma proposta de desenvolvimento territorial sustentável, o projeto do TBC nas comunidades ainda está aperfeiçoando as atividades no sentido de contrapor os modelos de segmentos turísticos tradicionais, buscando o protagonismo comunitário na organização de divulgação do roteiro e sua realização. A Figura 8 ilustrada a baixo mostra um mapa confeccionado pela comunidade local juntamente ao Ecomuseu da Amazônia, onde está selecionado para as visitações os pontos que são considerados patrimônio natural e cultural dessas comunidades. A imagem ilustra os saberes e fazeres da comunidade, além de retratar também a paisagem da porção ribeirinha da ilha de Cotijuba. 


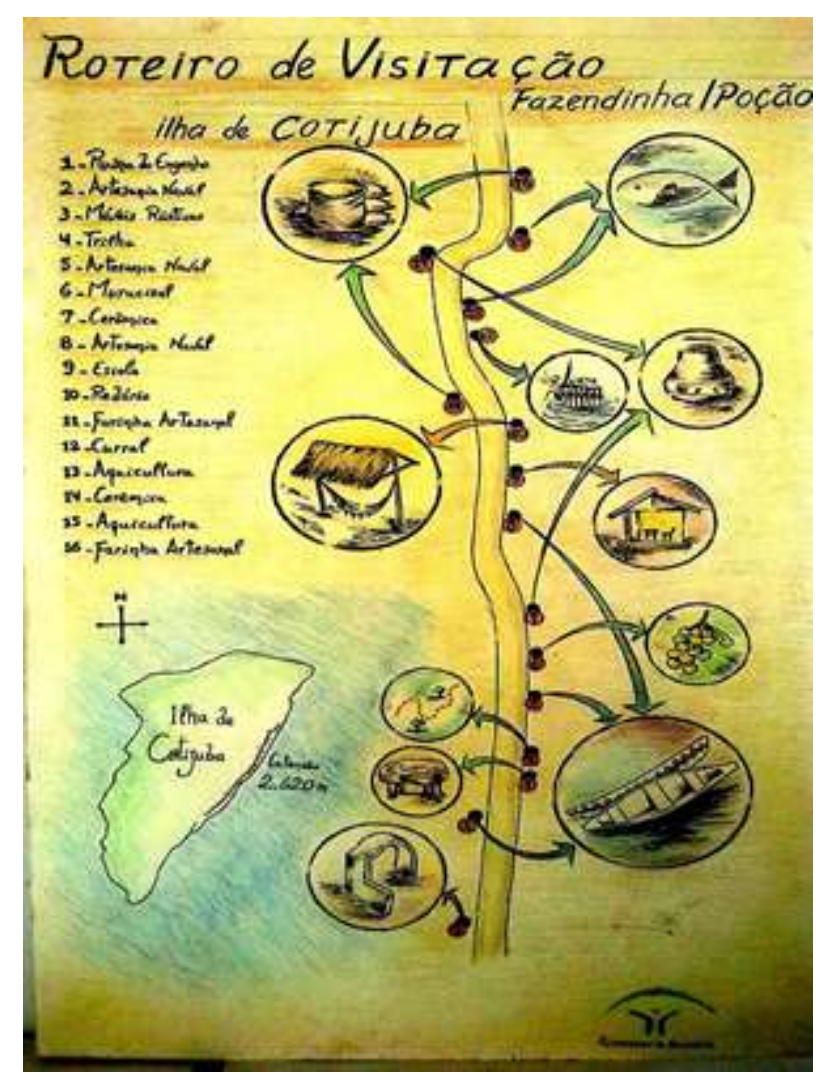

FIGURA 8

Biomapa do roteiro de visitação

Ecomuseu da Amazônia (2016)

Entendendo a realidade atual que a ilha de Cotijuba vem passando nos últimos anos, com a gradativa expansão de uma atividade turística desorganizada que aglutina na ilha sem o acompanhamento de seus impactos sobre o patrimônio cultural e natural da ilha, o projeto de TBC passa ser uma possibilidade de proteção e organização das atividades turísticas que ainda estão por aglutinar-se nas porções mais remotas de Cotijuba. Com efeito, convém lembrar, que o projeto do TBC nas comunidades de Poção e Fazendinha é o único instrumento de ordenamento realizado pelo estado no sentido que acompanhar os impactos e os benefícios causados pela atividade turística.

Para além dos sujeitos sociais e o capital, o Estado se configura também em um dos principais sujeitos da ação da produção do espaço. Dessa forma, entende-se aqui, que os agentes que realizam a representação do espaço, dinamizam a reprodução da vida e repertoriam as espacialidades e temporalidades no espaço concebido, que não é, de maneira alguma, apartado do percebido e do vivido.

\section{CONSIDERAÇÕES FINAIS}

$\mathrm{Na}$ divisão espacial do trabalho, as maiores ilhas em extensão de Belém passam a adquirir o papel de espaço de lazer, no mais, com o avanço da metropolização através de maiores facilidades de acesso físico e de relações urbanas nas ilhas, o tecido urbano passa a se espraiar cada vez mais mudando as relações antes estabelecidas ali, o que não admite mais uma total fuga do tempo rápido da metrópole, uma vez que a metrópole ali já está se reproduzindo.

O cotidiano ilhéu que na paisagem muito se assimila ao cotidiano do continente, mas em detalhes apresenta, nas suas relações, um abismo de diferenciações a medida que ali existente e resistente ao 
espraiamento do tecido urbano, encontra-se a natureza, as praias, uma vegetação ainda densa. Aspectos naturais que resistem ao tempo e as novas relações estabelecidas.

As coexistências na ilha se apresentam como resistência de um modelo de desenvolvimento a partir do que podem abstrair da atividade que coube à Ilha a partir das facilidades de acesso: a atividade turística. De acordo com os moradores, o modelo de segunda residência cresce cada vez mais dando o aspecto que o turismo está ficando gradativamente decadente. Quando o que mudou foi o modelo de turismo ali realizado.

As permanências se mostram desenhadas na paisagem quando assim se afasta do porto. Pescadores, agricultores ainda resistem na ilha. Porém, a produção de moradia e a especulação imobiliária é uma realidade que está se intensificando para o interior, causando desmatamento, aumento de produção de dejetos, produção de lixo. Dentre todos esses aspectos também se mostram presentes os espaços de representação urbanos.

Como espaço de vivência de antigos agricultores da colônia reformatória, migrantes de outras ilhas, da periferia de Belém, e donos de casas de veraneio, a ilha carece urgentemente de um ordenamento territorial que leve em conta seu patrimônio natural não esquecendo da necessidade de desenvolvimento socioespacial para seus moradores.

\section{REFERÊNCIAS}

Brasil. Ministério do Meio Ambiente. Ministério da Indústria, Comércio e Turismo. Ibama. Embratur. Diretrizespara uma politica nacional de ecoturismo. Brasília: EMBRATUR, 1994. 48 p.

Cruz, r. H. S. (2008) Turismo sustentável na Amazônia: o contexto do desenvolvimento endógeno. In: figueiredo, 1. S. (Org.). Turismo, lazer e planejamento urbano e regional. Belém: NAEA, p. 133- 146.

Diegues, a. C. (1998) Ilhas e mares. simbolismo e imaginário. São Paulo: Hucitec, 1998.

Guerra, g. (2004) Ilhas estuarinas e ocupação humana. Belém: NAEA/UFPA.

Hüffner, p. G.J. (2011) Estudo sobre os impactos do turismo em áreas naturais em processo de urbanização: o caso da ilha de Cotijuba, Belém - PA. [Dissertação de Mestrado em Desenvolvimento e Meio Ambiente Urbano, Universidade da Amazônia]. Belém, Pará, Brasil.

Lefebvre, h. (2016) O direito à cidade. São Paulo: Nebli.

Lefebvre, h. (2004). A Revolução Urbana. Belo Horizonte: EDUFMG.

Melo, o. Do c. (2010) A comunidade e a construção do lugar na Ilha de Cotijuba (PA). [Dissertação de Mestrado em Geografia, Programa de Pós-graduação em Geografia, Universidade Federal do Pará] Belém, Pará, Brasil.

Mielke, e. J. C. (2009) Desenvolvimento Turistico de Base Comunitária (v.1, p.190.). Átomo \& Alínea.

Paes-luchiari, m. T. D. (1999) O lugar no mundo contemporâneo - turismo e urbanização em Ubatuba/SP. [Tese de doutorado - IFCH, Unicamp]. Campinas. 222f.

Ribeiro, w. De o.(2007) Ordem e desordem do território turístico: a chegada do estranho e os conflitos de territorialidade na orla oeste de Mosqueiro. [Dissertação de Mestrado - Universidade Federal do Pará]. Belém, Pará, Brasil.

SILVA, Ivaldo das Dores. (2001) Massificação Do Lazer Em Areas Naturais Amazônicas E Suas Repercussões Ambientais: o caso da ilha de Cotijuba em Belém. [Dissertação de Mestrado, Programa de pós Graduação em Meio Ambiente, Universidade federal do Ceará]. Fortaleza, Ceará, Brasil.

Trindade junior, s-c. C. (2008) De volta ao rio: estratégias de gestão e de (re)apropriação do espaço urbano na área central de Belém. In: ; TAVARES, M. G. C. (Org.). Cidades ribeirinhas na Amazônia: mudanças epermanências. (1 ed., v. 1, p. 145-156.). EDUFPA,

Trindade junior, s-c. C. (1998). A cidade dispersa: os novos espaços de assentamentos em Belém e a reestruturação metropolitana. [Tese de Doutorado em Geografia Humana - Faculdade de Filosofia, Letras e Ciências Humanas, Universidade de São Paulo], São Paulo, Brasil.

Trindade junior, s-c. C. (2016). Formação metropolitana de Belém (1960-1997) (1. ed.). Paka-Tatu. 


\section{Notas}

[1] "Cotijuba é a terceira maior ilha em dimensão territorial do arquipélago belenense (ficando atrás de Mosqueiro com 21.254,67 ha e Caratateua-Outeiro 3.165,12 ha)" (MELO, 2010, p. 20).

[2] A divisão espacial do trabalho, de acordo com Santos (2012), em qualquer escala, compõe o papel e importância que atividades terciárias possuem em cada momento histórico, entre as relaçôes de intercâmbio e a localização dos instrumentos e agentes.

[3] O Ecomuseu da Amazônia é um programa vinculado à Fundação Centro de Referência em Educação Ambiental -Escola Bosque Professor Eidorfe Moreira da Prefeitura Municipal de Belém. O programa atua por meio de projetos desde 2007 na região insular de Belém, principalmente nas ilhas de Caratateua, Mosqueiro e Cotijuba, com ações que visam o desenvolvimento local com base na sustentabilidade socioambiental e valorização cultural, contribuindo para a fixação do homem em sua terra. Surge como uma proposta que enfatiza a museologia social difundida na França nos anos de 1970/80, sendo fundamentado no movimento dos museus ao ar livre, da redescoberta patrimonial no Reino Unido e na gênese do ambientalismo na museologia (BELÉM, 2016, p. 3). 